\title{
The Family Tree Grows Tall: A Salute to Family Physicians Inducted Into the National Academy of Medicine
}

Ann Fam Med 2020;18:4. https://doi.org/10.1370/afm.2512.

$\mathrm{T}$ The Annals of Family Medicine takes special pride in congratulating the four outstanding practitioners of family medicine who were elected to the National Academy of Medicine in October 2019. We are grateful for all of their contributions to family medicine and to the Annals.

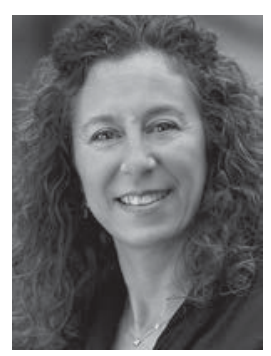

Deborah J. Cohen, PhD, a collaborative leader in qualitative and mixed methods primary care research and a professor and research vice chair of family medicine in the Oregon Health \& Science University School of Medicine, is known as an innovative change agent in her field. With nearly 100 peer-reviewed publications and more than $\$ 25$ million in grant funding from the National Institutes of Health, Agency for Healthcare Research (AHRQ), Quality Patient-Centered Outcomes Research Institute, and Robert Wood Johnson Foundation, her research focuses on the implementation of clinical innovations, including novel technological systems-assessing their impact on patient care-and understanding how to scale up successful transformation efforts. Cohen serves as a principal investigator evaluating the EvidenceNOW initiative, which aims to transform and advance heart health in more than 1,200 primary care practices across the country. She also served for 12 years as associate editor for Annals of Family Medicine.

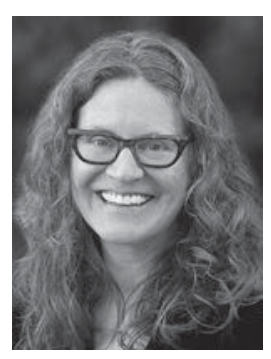

Laura M. Gottlieb, MD, MPH, is an associate professor of family and community medicine at the University of California, San Francisco. Her research explores health care sector programs and policies related to identifying and addressing social risk factors in the context of care delivery. She is the founding director of the Social Interventions Research and Evaluation Network, a national research network that advances research on health care strategies to improve social conditions. Dr Gottlieb is also associate director of the Robert Wood Johnson Foundation Evidence for Action National Program Office.

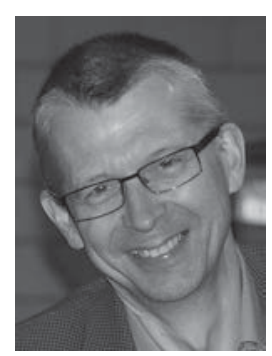

Jan De Maeseneer, MD, PhD (1952), worked for 40 years as a family physician in a community health center in a deprived area of Ghent (Belgium). He was head of the Department of Family Medicine and Primary Health Care from 1991 to 2017 at Ghent University. Since 1997 he has been involved in the Primafamed Network in Africa, supporting development of family medicine and primary care in over 20 African countries. He is the chair of the Expert Panel on Effective Ways of Investing in Health, advising the European Commission, and a member of the Global Forum on Innovation of Health Professional Education.

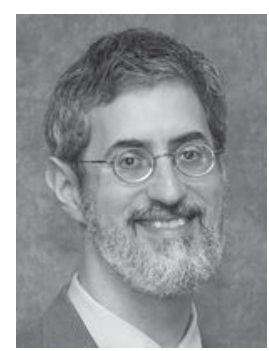

David Meyers, MD, FAAF, is a board-certified family physician and health services researcher who serves as the chief physician and acting deputy director of the US Agency for Healthcare Research and Quality. At AHRQ, while leading strategic development for the agency, he enjoys working with experts in primary care, digital health, prevention, patient safety, data analytics, and practice improvement to advance quality, safety, and value in health care delivery. His own research has focused on primary care organization and delivery. Before joining AHRQ in 2004, he completed a fellowship in health policy and research and then practiced full-scope family medicine in community health centers in Washington, DC, where he developed a practice-based research network focused on improving health and health care for underserved communities.

To read or post commentaries in response to this article, see it online at http://www.AnnFamMed.org/content/18/1/4.

Key words: National Academy of Medicine Inductees; awards

Submitted December 2, 2019; accepted December 3, 2019. 